\title{
A “PRIMARIZAÇÃO” DA PAUTA EXPORTADORA E A QUESTÃO DA DOENÇA HOLANDESA: ANÁLISE DOS IMPACTOS DA CRISE FINANCEIRA DE 2008 SOBRE AS EXPORTAÇÕES BRASILEIRAS
}

\author{
Dinorá Baldo de Faveri* \\ Max Cardoso De Resende \\ Silvio Ferraz Cário
}

\section{Resumo}

Este trabalho investiga os impactos da crise financeira internacional de 2008 sobre a primarização das exportações e os sintomas da doença holandesa para o Brasil em termos dos valores exportados e das participações relativas no saldo total de exportações brasileiras de diversas commodities e de produtos manufaturados. Para isso, o trabalho utiliza análise das estatísticas descritivas dessas variáveis e testes de mudança estrutural (Bai-Perron (2003) e ZivotAndrews (2002)) para o período de janeiro de 2000 a junho de 2014 . O trabalho sugere que há uma redução na participação de produtos industrializados em relação aos intensivos em recursos naturais e que esta trajetória não se modificou com a crise, e esta não foi capaz de provocar mudanças estruturais significativas na trajetória de exportação dos produtos avaliados.

Palavras-chave: Exportação; doença holandesa; crise financeira.

\begin{abstract}
This paper investigates the impact of the international financial crisis of 2008 on the insourcing of exports and the symptoms of Dutch Disease in Brazil in terms of export values and the relative share in the total balance of Brazilian exports of various commodities and manufactured goods. For this, the work uses analysis of descriptive statistics of these variables and structural change tests (Bai-Perron (2003) and Zivot-Andrews (2002)) for the period J anuary 2000 to J une 2014. The study suggests that there is a reduction in the share of processed products for intensive natural resources and that this trend has not changed with the crisis, and it was not able to bring about significant structural changes in the export path of this product.
\end{abstract}

Key-words: Exports, dutch disease; financial crisis.

Classificação J EL: F10, F18, O10

\footnotetext{
* UFSC/UDESC
} 


\section{Introdução}

Uma série de estudos feitos no Brasil no período mais recente sobre a participação da indústria na estrutura produtiva tem apontado para uma perda da importância relativa desta na economia, enquanto há um aumento das commodities, fenômeno este que é conhecido como doença holandesa.

A literatura sobre doença holandesa mostra que países com abundância em recursos naturais, por apresentarem expressivas vantagens comparativas na produção destes bens, podem incorrer na especialização produtiva de commodities em detrimento de bens manufaturados com maior valor agregado. Assim, com o deslocamento dos fatores de produção para os setores de menor conteúdo tecnológico estes se expandem, enquanto os outros, em especial a indústria observa enfraquecimento em seu nível de atividade produtiva.

Segundo dados do Ministério do Desenvolvimento, Indústria e Comércio Exterior (MDIC, 2014), a participação de bens de capital nas transações correntes reduziu de 13,98\% em junho de 2000 para 6,02\% em junho de 2014, enquanto nos produtos primários, por exemplo com a soja em grão ocorreu fenômeno contrário, aumentando de 7,10\% para 17,45\%, ou seja, uma expansão de $145 \%$ e que tal situação é influenciada por aspectos da estrutura econômica nacional e internacional. A hipótese que norteia esse artigo é que a crise de 2008 não atenuou o processo de "reprimarização" da pauta exportadora brasileira como outras crises passadas fizeram, como a crise de 29 e crises do petróleo, as quais promoveram políticas pró-industrialização.

Diante desta perspectiva, este trabalho analisa o volume das principais commodities brasileiras exportadas (soja em grão, café, açúcar, carne bovina e minério de ferro) e de produtos industrializados (bens de capital e de consumo duráveis) entre janeiro de 2000 e junho de 2014 e, verifica se a crise financeira deflagrada em 2008 promoveu alguma mudança estrutural nestes setores, na questão da "primarização" da pauta exportadora e consequentemente na problemática da doença holandesa.

Para alcançar os objetivos, o trabalho está estruturado em cinco seções, além desta Introdução. A Seção 2 traz uma breve revisão teórica e empírica apontados pela literatura acerca da problemática da doença holandesa. A Seção 3 apresenta os dados que sinalizam para a perda de força do setor de manufaturados no país e a consequente expansão do setor de recursos naturais a partir dos anos 2000 para avaliar a questão da "primarização" da pauta exportadora nacional e da doença holandesa. A Seção 4 identifica o período das mudanças estruturais apontados pelos testes de raiz unitária de Zivot - Andrews (1992) e múltiplas quebras de Bai-Perron (2003) e verificar se a crise financeira de 2008 teve impacto nas séries analisadas. E por fim, a Seção 5 apresenta as conclusões do trabalho.

\section{Tratamento Analítico sobre Doença Holandesa no Brasil: contribuição ao debate}

No curso do desenvolvimento brasileiro, a estrutura industrial percorreu da segunda metade dos anos 1950 a 1980 trajetória marcada por processo de catching-up da estrutura industrial mundial, marcada por forte processo concorrencial das empresas transnacionais no mundo pós II Grande Guerra. 
Neste contexto, firmou-se um período da substituição de importações, quando o crescimento foi acompanhando por uma diversificação da estrutura produtiva significativa na indústria. Contudo, os anos posteriores foram marcado por um processo de falling behind, cuja estrutura produtiva industrial perdeu dinamismo, distanciando, ao longo dos anos 80, do novo padrão tecnoprodutivo que se firmava em nível mundial. O novo paradigma impôs novos requerimentos, cuja estrutura da economia brasileira não apresentava requerimentos necessários para adentrá-lo (AREND; FONSECA, 2012).

Nos anos 90 se observa uma mudança na economia brasileira com a interação entre a globalização, abertura da economia, privatizações e o papel do Estado foi aos poucos se reduzindo, quer seja pelo processo de privatização quer seja pela coordenação do setor privado (SARTI; HIRATUKA, 2010 e 2011). Inicia-se então uma nova fase em um regime de crescimento baseado nos mercados desregulados, resultando em crescimento pífio longe de retomar o dinamismo. Neste período marcado pela globalização, os segmentos mais dinâmicos da indústria brasileira não coincidem, em grande parte, com aqueles dos países desenvolvidos, distanciando-se do padrão reinante na economia mundial (CARNEIRO, 2008).

Em particular, na segunda metade dos anos 90, acentua-se o processo de internacionalização da economia com os IDEs (Investimentos Diretos Estrangeiros), apesar de terem financiado o déficit de transações correntes, limitou a competitividade da indústria nacional porque boa parte desses investimentos foi direcionada aos setores de serviços públicos e infraestrutura via privatizações e outra parte significativa se concentrou nas aquisições de empresas não contribuindo para formação bruta de capital fixo. O dinamismo observado nos fluxos de IDE ao longo dos anos 90 e 2000 acentuou uma das características do padrão de inserção externa brasileira no que diz respeito à assimetria existente entre, de um lado, a elevada presença de empresas estrangeiras na estrutura produtiva brasileira e, de outro, o baixo grau de internacionalização produtiva das empresas nacionais. Assim, poucas filiais brasileiras assumiram o papel de fornecedoras globais dentro da organização mundial (SARTI; HIRATUKA, 2010 e 2011).

Neste contexto, soma-se a perda de capacidade de intervenção do Estado na economia, importante instrumento fomentador da demanda efetiva. Soma-se a redução da capacidade produção, de consumo e investimento próprio e de induzir e coordenar investimentos empresariais privados. Reduziu-se a capacidade do Estado impulsionar e financiar elos produtivos em momentos de expansão, bem como se posicionar com políticas anticíclicas em momentos de crise econômica. Além de se verificar a deterioração da infraestrutura transporte, comunicação, energia e em ciência e tecnologia (C\&T) (CARNEIRO, 2008).

Enquanto, os países desenvolvidos, adentraram os anos 1990 e 2000 com avanços significativos na indústria de material eletrônico e de comunicação, tecnologia da informação e microeletrônica, constituindo no atual paradigma tecno-produtivo mundial, nos países em desenvolvimento houve aprofundamento tecnológico em setores signatários da revolução tecnoprodutiva anterior (máquinas e aparelhos elétricos, material de transporte). $\mathrm{O}$ 
Brasil apesar de acompanhar essas duas últimas tendências não conseguiu incorporar de forma significativa o setor tecnológico: material eletrônico e de comunicação. Além disso, atribuiu maior empenho nas indústrias com menor conteúdo tecnológico, ou seja, nas indústrias tradicionais baseadas em recursos naturais.

As empresas reagiram às novas condições imposta racionalizando os processos produtivos, aprofundando as especializações produtivas, seguida por processos de aquisições de máquinas e equipamentos, facilitadas pela apreciação cambial e redução de barreiras tarifárias e não-tarifárias. Além disso, muitas empresas em diferentes setores procuraram-se aliar a sócios estrangeiros para complementação de linhas de produção e de prestação de serviços no mercado interno (LAPLANE e SARTI, 2006). A despeito destes procedimentos a estrutura industrial foi cada vez mais se consolidando em especialização regressiva. As atividades especializadas em atividades intensivas de recursos naturais, o abandono e ou redução dos esforços inovativos, e a menor exposição à concorrência externa contribuíram para o perfil da estrutura existente (CANEIRO, 2008; COMIN, 2011 e CANO, 2014). A estrutura industrial adentra os anos 2000 com perfil de relativa rigidez e heterogeneidade produtiva com aprofundamento da especialização produtiva regressiva em detrimento de setores mais dinâmicos (AREND, 2014).

Neste contexto, desde 2003 a taxa de câmbio vem se apreciando em termos reais e assim mesmo as exportações continuaram sua trajetória de alta. Diante desse contexto, estudo de Bresser Pereira e Marconi (2008, p. 8) aponta a ocorrência doença holandesa no Brasil. Segundo estes autores esta ocorre a partir da "sobreapreciação crônica da taxa de câmbio causada pela abundância de recursos naturais e humanos baratos, compatíveis com uma taxa de câmbio inferior àquela que viabilizaria as demais indústrias de bens comercializáveis". Nesse sentido, a doença holandesa constitui em um fenômeno causado pela abundância de recursos naturais que geram vantagens comparativas ao país que os possui podendo conduzi-lo a se especializar na produção destes bens abrindo mão de se industrializar.

O estudo desenvolvimento por Bresser Pereira e Marconi (2008) segue os estudos pioneiros de Corden e Neary (1982) que desenvolveram o primeiro modelo de doença holandesa, que foi aprimorado por Corden (1984) e nele constam três setores: o de produtos não comercializáveis, o de produtos comercializáveis que cresce rapidamente (produtos naturais com vantagens comparativas) e o de comercializáveis que cresce mais lentamente (indústria e demais setores da agricultura e extração). O setor que produz recursos naturais (comercializáveis que cresce à frente dos demais) tende a elevar de forma rápida as receitas de exportação levando à apreciação da taxa de câmbio e os dois fatores ajudar a elevar a renda, e, como resultado, desestímulo à exportação no setor de manufaturados (comercializáveis que crescem mais lentamente).

Segundo Bresser-Pereira (2007) a doença holandesa apresenta três fatores determinantes, onde o principal constitui na sobreapreciação da taxa de câmbio que é uma profunda falha de mercado decorrente da existência de rendas ricardianas que tem possibilidade de enfraquecer a economia do país por um tempo não determinado. $\mathrm{O}$ outro fator é o da possibilidade de neutralizar a 
doença por meio da administração da taxa de câmbio e da criação de um imposto sobre as vendas do mesmo que desloque sua curva de oferta para cima. $\mathrm{O}$ último fator a ser considerado é que o fenômeno da doença holandesa também é resultado da mão-de-obra barata e não somente da abundância de recurso naturais.

Para Bresser Pereira e Marconi, (2008), o Brasil pode ser afetado pela doença holandesa, visto que possui vantagens comparativas em commodities. Esta falha de mercado era controlada, antes dos anos 90, por política de controles tarifários, alfandegários e cambiais, taxando receita de exportações de commodities e desestimulando a importação de produtos manufaturados, e como consequência incentivava à produção interna. A partir de 1990, com o fim destes mecanismos foi perdido o controle sobre os efeitos da doença holandesa. No período que segue, sobretudo pós 2003 e em boa parte dos anos até 2014 encontram-se, na economia brasileira, sintomas da doença holandesa postos em: apreciação da taxa de câmbio em virtude do aumento das exportações; aumento da balança comercial das commodities e queda dos manufaturados; a balança comercial de commodities evoluiu de forma desassociada da taxa de câmbio; aumento dos preços e quantum das exportações de commodities mais do que os dos manufaturados; aumento da participação das commodities no valor adicionado total; queda da participação dos manufaturados comercializáveis no valor adicional de manufaturados.

Conforme Bresser Pereira e Gala (2010) a tendência de sobrevalorização da taxa de câmbio, por um lado sugere maior equilíbrio na conta corrente do balanço de pagamento, por outro não é compatível com a competitividade de industrial e alimenta a desindustrialização da estrutura produtiva nacional. Oreiro e Feijó (2010) concordam com o argumento de que a desindustrialização causada pela "doença holandesa" está estreitamente relacionada com déficits comerciais na indústria e superávit comercial no setor primário, isso porque a fartura de recursos naturais pode levar a uma diminuição da participação da indústria no emprego e no valor adicionado por meio da apreciação do câmbio uma vez que com moeda apreciada desfavorece as importações gerando déficits comerciais e perda de competitividade industrial.

Assim, a desindustrialização causada pela doença holandesa e a desindustrialização precoce (FERRAZ, et al 2004) podem ser consideradas sinônimas porque a segunda inicia seu processo (nos países em desenvolvimento) quando a renda per capita é inferior à dos países em desenvolvimento no mesmo instante em que estes passaram pela desindustrialização. E, nos países onde se observou a doença holandesa, o processo começa antes de terem alcançado o "ponto de maturidade", ou seja, sem terem enfraquecido as possibilidades de desenvolvimento econômico proporcionado pelo processo de industrialização.

Em verdade, existem duas situações de doença holandesa, uma no caso de os países nunca terem se industrializado por conta de elevadas exportações de recurso natural, e outra onde os países conseguiram atingir a industrialização por um determinado período e em seguida começaram a se desindustrializar antes. Na primeira situação, o país nunca neutralizou a doença holandesa que assume um caráter relativamente permanente. A Venezuela e a Arábia Saudita 
são exemplos de países que conseguiram acumular capital devido a exportação de recursos naturais, mas não possuem indústria de bens comercializáveis. Na segunda situação, o país tem abastados recursos naturais e utiliza para exportação e assim mesmo se industrializou, e, portanto, a doença foi neutralizada com o auxílio das tarifas de importação e subsídios à exportação. Porém, por causa dos subsídios, o país foi acusado de 'protecionismo', e então deixa de lado o processo de neutralização para respeitar o comércio liberal (BRESSER PEREIRA; GALA, 2010 e BRESSER PEREIRA et al, 2009).

A doença holandesa representaria, no entanto, uma anomalia, pois significaria uma perda de participação da indústria não associada ao aumento da renda per capita. Nos países avançados, Holanda e Noruega (petróleo), Espanha e Itália (Turismo) observou-se uma apreciação das moedas e uma maior especialização nesses setores com queda da importância do setor manufatureiro de bens comencializáveis. Na América Latina aparece outra forma da doença holandesa, a partir dos anos 1990 com supressão radical da proteção à indústria - tarifária e não tarifária - a desregulação do IDE, as privatizações, apreciação das moedas locais, assim, essas políticas induziram a aderência da estrutura produtiva à dotação de fatores existentes com ênfase nos recursos naturais. Assim, o que se observou foi um crescimento da indústria de transformação muito baixo, e esse foi o principal responsável pela desindustrialização precoce (BRESSER PEREIRA; GALA, 2010 e BRESSER PEREIRA et al, 2009).

Segundo Bresser Pereira (2007) existem duas formas de neutralização da doença holandesa, uma é a criação de imposto ou contribuição sobre a venda dos produtos, o que significa à diferença porcentual entre a taxa de câmbio de equilíbrio corrente que seu custo mais baixo proporciona e a taxa de câmbio de equilíbrio industrial que viabiliza setores comercializáveis no estado da arte da tecnologia, outra forma é criar um fundo internacional de ativos financeiros para inibir que a entrada no país venha a apreciar novamente e a taxa de câmbio. A criação do imposto é uma maneira direta de neutralizar a doença holandesa, onde se espera que ele desloque a curva de oferta do produto para cima aproximando o custo marginal dos demais produtos, ou seja, igualar a taxa de câmbio de equilíbrio corrente a de equilíbrio industrial.

Por fim, cabe ressaltar, que há estudos que sinalizam positivamente e outros ao contrário da ocorrência da doença holandesa. Destaque para o estudo de Veríssimo (2010) que investigou empiricamente a doença holandesa (Dutch disease) brasileira no período de 1995 a 2009. Os resultados demonstraram que há evidências da ocorrência da doença holandesa e de seus efeitos. As exportações bem como os preços das commodities, explicam a apreciação cambial e o desempenho econômico. Os resultados sugerem que para perceber indícios da doença é preciso utilizar indicadores de preços e exportações de commodities tais como alimentos, matérias-primas, minerais e energia. Assim como, ressalta-se a visão contrária, com os resultados do estudo de Strackn e De Azevedo (2012). Através de análises de dados relacionados à estrutura industrial brasileira, tais autores concluíram que não ocorrera mudança significativa na participação do setor industrial no PIB brasileiro, apesar do aumento de reprimarização da pauta de exportações. Portanto, o fenômeno da doença holandesa não faz parte da economia brasileira, porque não se constatou 
alteração na indústria a partir de 2005.

Recentemente, outras abordagens buscam interpretar o processo de perda de participação da indústria em relação ao PIB para além da visão clássica da doença holandesa. Nesse contexto, Bonelli e Pessôa (2010) são defensores de que a desindustrialização no país é um fenômeno de longo prazo e de convergência à média internacional, com exceção a China. Segundo os autores, o país estava sobreindustrializado nos anos 1970 e essa retração ocorrida a partir da década seguinte é um processo de correção natural e independente da política macroeconômica. Contudo, enquanto a desaceleração mundial ocorre com uma indústria intensiva em capital e com elevado nível de renda, no Brasil esse mesmo processo ocorre com uma indústria pouco intensiva em capital e com problemas de heterogeneidade de renda, que pode resultar em uma situação de sub-industrialização em relação aos padrões mundiais.

Por sua vez, Morceiro (2012) pesquisou o processo de desindustrialização brasileira no período entre 2000 a 2011. A constatação é que o processo está em curso desde 2005 apresentando forte evolução entre 2009 a 2011. Verifica-se, desde o início de 2000, reprimarização da pauta de exportações, enquanto as importações concentram-se em produtos de maior intensidade tecnológica. Conforme o autor, o processo de desindustrialização brasileira é explicado pela queda do valor adicionado no PIB das manufaturas, tanto em valores correntes quanto em valores constantes, pelo declínio da indústria de transformação local no comércio exterior e pela taxa de câmbio sobrevalorizada. No entanto, existem outros fatores relacionados a desindustrialização, tais como, altas taxas de juros, complexa e alta carga tributária e infraestrutura ineficiente e defasada.

Torres e Cavalieri (2015) argumentaram que, apesar da causa mais conhecida do processo de desindustrialização ser a da doença holandesa, o regime macroeconômico e o fechamento de plantas industriais também são considerados causas do processo de desindustrialização. O regime torna-se uma causa quando o câmbio se aprecia via superávit na balança de capital, e também quando o país tem vantagens comparativas, fazendo o setor abundante em recursos naturais ser o único competitivo no mercado internacional, e por consequência desestimula o desenvolvimento de outros setores industriais. Visando aproveitar as vantagens de redução de custos proporcionadas pela liberalização comercial e a divisão internacional do trabalho, empresas nacionais optam por produzir fora do país, ou terceirizar uma parcela de sua produção. O fechamento de plantas industriais é apontado como outra causa da desindustrialização.

\section{O comportamento da balança comercial brasileira no século XXI}

A evolução do PIB mundial, ao longo dos anos 2000, mostra que, nunca antes na história recente da humanidade, o mundo experimentou um ciclo de crescimento alto e sustentando por um período tão longo, com uma taxa média de crescimento anual superior a 5\%, entre os anos de 2003 e 2009, sendo a China e a Índia as principais fomentadoras dessa expansão econômica mundial.

Quanto ao Brasil, no final da década de 1990, depois de um período de crises econômicas, o país retomou o crescimento, aumentando o PIB em aproximadamente 33\%, passando de US\$ 770 bilhões em 2000, para US\$ 1 
trilhão e 300 bilhões em 2008. Para Carneiro (2010) esse crescimento foi resultado de um contexto internacional favorável aos países emergentes visto o aumento a demanda externa, sobretudo nos anos 2002 e 2003 e que se estendeu por mais o biênio seguinte. Esses países fizeram uso da sua capacidade de exportação para aumentar seu saldo comercial e, após 2005 o aumento do PIB é explicado pela demanda doméstica e não mais pela demanda externa.

Apesar de o real estar valorizado em relação ao dólar, o saldo da balança comercial foi positivo no período compreendido entre 2000 e 2008 (ver Gráfico 3.1), o que é explicado pela rápida recuperação da economia mundial no início da década de 1990.

\section{Gráfico 3.1 Balança comercial no período de 2000 até 2014 (em milhões de US\$, FOB)}

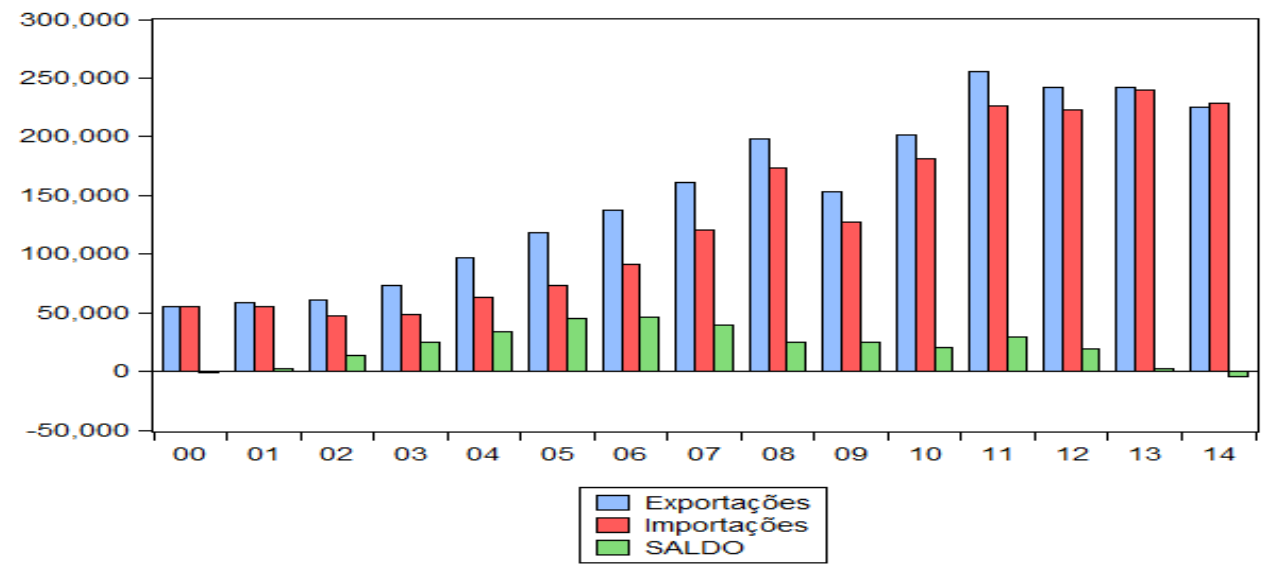

Fonte: Elaborado pelos autores com base nos dados de Ipeadata.

A crise alcança o Brasil por meio da redução dos fluxos de capitais fundamentais para financiar os déficits nas contas correntes e manter as taxas de investimento - e, diminuição dos preços internacionais das commodities que desestimula as exportações (PASTORE; PINOTTI, 2008).

Analisando novamente a balança comercial brasileira após 2008, o contexto internacional impactou o coeficiente importado e exportado como pode ser notado no Gráfico 3.1. Ainda assim, em 2009 ocorreu um superávit em relação ao ano de 2008 e com perspectivas positivas do Banco Central para os próximos anos. Essas expectativas positivas sucederam-se até o ano de 2013 e apenas em 2014 houve um déficit na balança comercial.

Nesse contexto de crise econômica mundial e nacional, busca-se analisar o volume das principais commodities brasileiras exportadas (soja em grão, café, açúcar, carne bovina e minério de ferro) e de produtos industrializados (bens de capital e de consumo duráveis) entre janeiro de 2000 ejunho de 2014 e verificar se essa crise promoveu alguma mudança estrutural nestes setores, na questão da "primarização" da pauta exportadora e consequentemente na problemática da doença holandesa.

\subsection{A primarização da pauta exportadora}

Um dos argumentos que sinalizam que o processo de desindustrialização está ocorrendo é a tendência de perda de participação dos bens manufaturados em relação ao valor financeiro total exportado pelo Brasil, enquanto que há um viés 
de alta para a participação de produtos primánios.

O Gráfico 3.2 retrata este cenário, ao mostrar a redução da participação nas exportações da indústria de bens de capital e de bens de consumo durável ao longo do período em análise, e que principalmente a partir do boom dos preços das commodities nos mercados internacionais, no início de 2002 , as exportações de produtos básicos cresceram à taxas bastante elevadas.

Em janeiro de 2000, as vendas no mercado internacional de bens de capital representavam cerca de 13\%, enquanto em meados de 2014 este valor estava em $6 \%$, ou seja, uma redução de mais de $50 \%$. Situação semelhante se apresentou para o setor de bens de consumo duráveis, que viu sua participação minguar, no mesmo período de $4,33 \%$ para $2,41 \%$, o que equivale a uma retração de quase $45 \%$.

Em termos de participação nos bens exportados pela economia brasileira, notase que o café perdeu importância relativa no valor médio anual do total exportado, encolhendo sua participação em cerca de $40 \%$, enquanto que a soja em grão e o minério de ferro aumentaram suas participações ao longo do período em análise, em respectivamente, $270 \%$ e 233\%. Em contrapartida, o açúcar e a carne bovina mantiveram um comportamento relativamente estável, oscilando em função dos preços praticados nos mercados internacionais e de barreiras fitossanitárias.

A partir da análise desses dados, percebe-se que enquanto o setor de manufaturados segue em declínio, o setor intensivo em recursos naturais segue sua trajetória de destaque, principalmente a indústria da soja e do minério de ferro, que respondiam juntas ao final de 2014 por quase $33 \%$ de todas as divisas arrecadadas com comércio internacional no país.

\section{Gráfico 3.2 (a) Evolução da participação de bens manufaturados no} total exportado do Brasil (\%) (01/2000-06/ 2014)

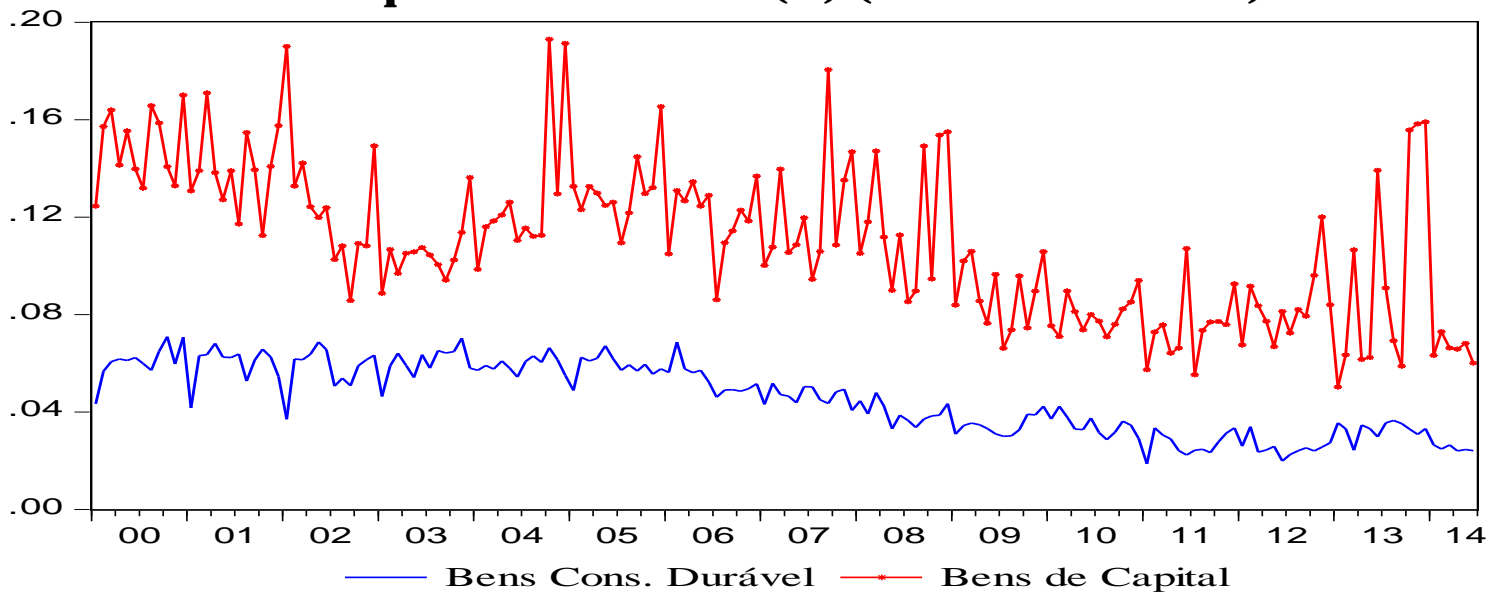




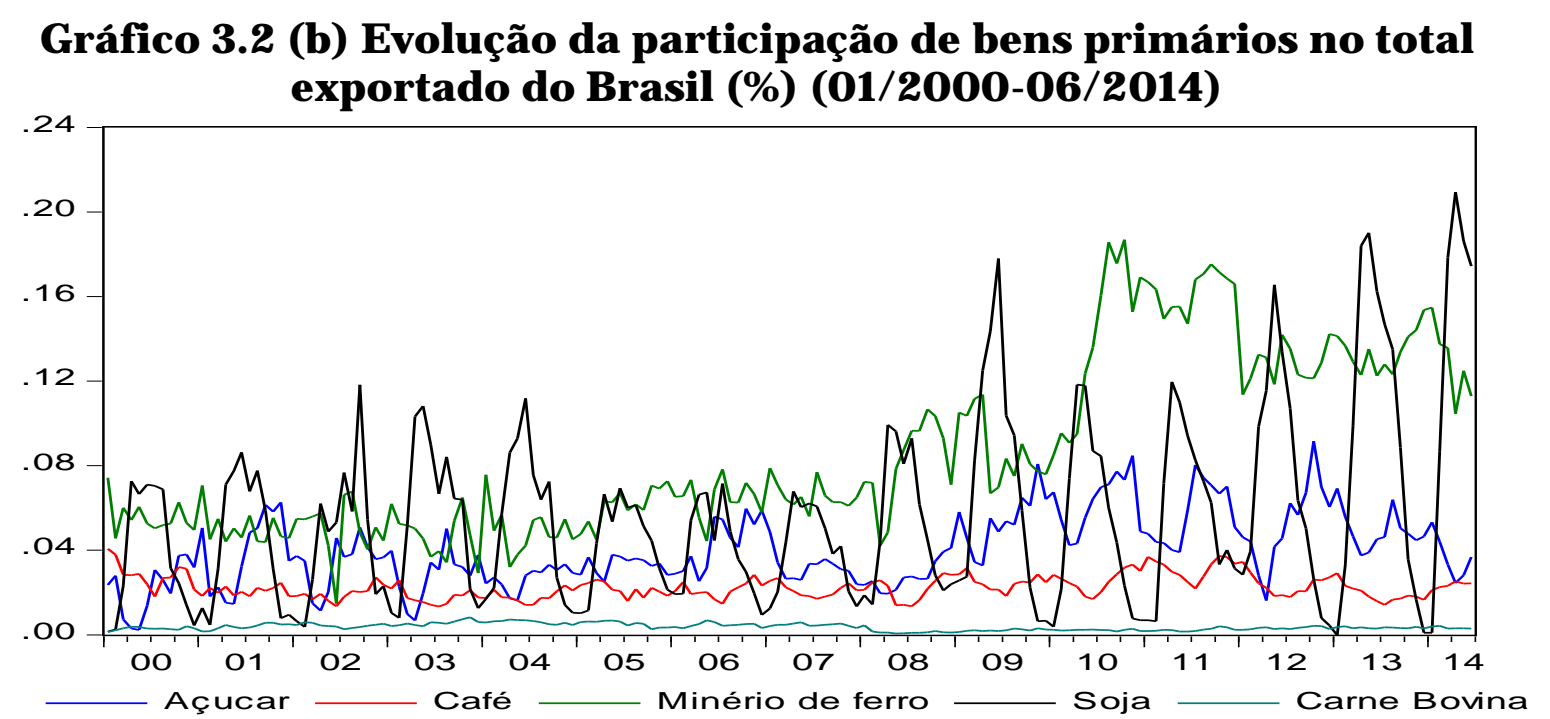

Fonte: Formatação própria a partir de dados do MDIC (2014).

Também merece destaque a forte volatilidade do volume das commodities em relação aos bens manufaturados, principalmente pós-crise de 2008, o que mostra que a especialização internacional em produtos primários implica em problemas de vulnerabilidade externa da economia brasileira, podendo ocasionar impactos significativos no saldo em transações correntes e, consequentemente, no resultado do balanço de pagamentos.

Conforme apresentado na Seção 2, o principal causador da maior participação de produtos básicos em relação aos manufaturados na pauta exportadora tem sido a valorização da taxa de câmbio, em conjunto com o efeito do aumento de preços das commodities associadas ao efeito China-Índia, a uma maior demanda por produtos agrícolas de países africanos e a aumento significativo dos custos de transporte. Outro fator que impulsionou a subida de preços no mercado agrícola é o forte subsídio dados pelos países do primeiro mundo a seus produtores, o que acaba por distorcer o preço final do bem, gerando uma elevação dos preços mundiais desses produtos. 


\section{Gráfico 3.3 Índices de preço e valores exportados (US\$ milhões FOB) dos produtos básicos}
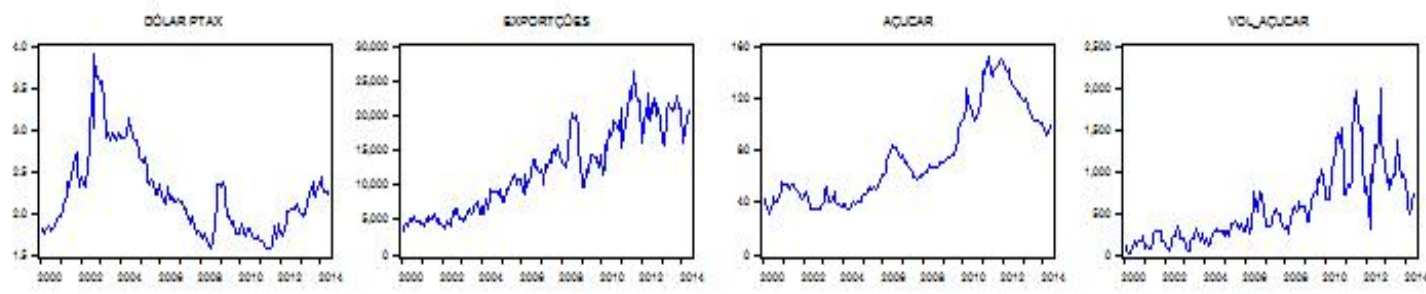

ext
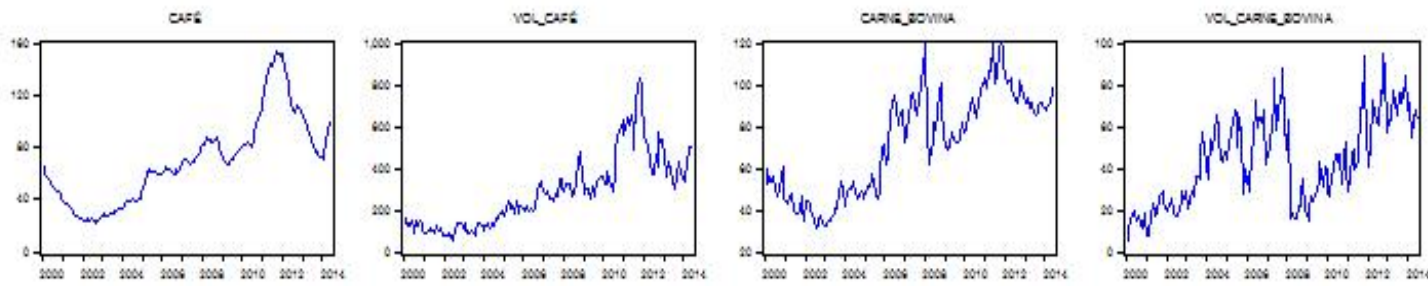

matad

vewancaso

50.14
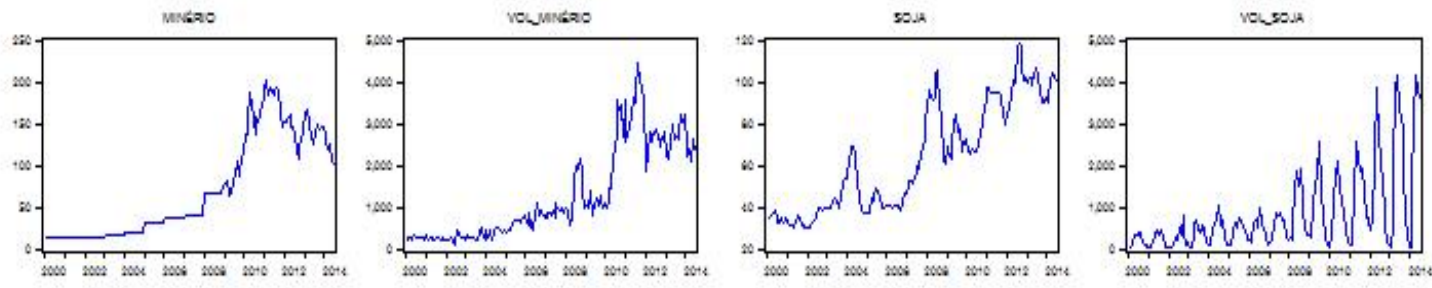

Fonte: Formatação própria a partir de dados do Fundo Monetário Internacional (FMI, 2016). Nota: Índices de preço específicos para cada setor tendo como data base 2014.06;

O Gráfico 3.3 mostra a evolução dos índices de preços e dos volumes reais exportados dos bens primários a partir de janeiro de 2000. No que tange a evolução dos primeinos, percebe-se uma trajetória ascendente que perdurou de 2002 à setembro de 2008. A soja em grão teve seu índice de preço majorado em quase $300 \%$, se elevando de 30.30 a tonelada métrica em janeiro de 2002 para 89.2 no mês da eclosão da crise financeira mundial, enquanto que o minério de ferro apresentou um aumento ainda maior, de 379\% e o café um pouco abaixo, $252 \%$. Os índices de preços do carne bovina e do açúcar também apresentaram comportamento semelhante, mas com elevações não tão expressivas quanto aos três primeiros produtos citados, aumentaram $92 \%$ e $52 \%$, respectivamente.

Tal comportamento ascendente é freado apenas no final de 2008 com a eclosão da crise financeira internacional (linha vertical preta nos gráficos), mas por um breve período de tempo, ocorrendo a retomada da trajetória ascendente a partir dos primeiros meses de 2010. A alta expressiva dos preços se propagou no aumento significativo das exportações dessas commodities, com uma participação média de $21 \%$ no total das exportações, no período analisado.

Quanto ao volume real exportado, o produto que mais se destacou no período em análise foi a soja, onde sua receita de exportação aumentou de uma média 330 milhões de dólares nos meses de safra para mais de 3.600 milhões em 2014 , ou seja, um aumento de quase $1200 \%$. No conjunto dos bens selecionados todos apresentaram forte expansão nos valores exportados, minério de ferro, 799,90\%, carne bovina, 1.157,49\%, açúcar 826,45\% e café 245\%. 
A Tabela 3.1 apresenta as estatísticas descritivas básicas dos preços internacionais e dos valores exportados das commodities selecionadas vigentes no período de 01/2000-06/2014 e nos sub-períodos 01/2000-09/2008 (précrise) e 10/2008-06/ 2014 (pós-crise).

Quando se analisa o período total e as sub-divisões propostas, observa-se que os preços médios das matérias-primas são bem mais elevados no período de póscrise, e que a volatilidade dos mesmos é bem menor neste período do que no anterior, fato este que terá grande influência nas receitas advindas do comércio destes bens. A queda acentuada na volatilidade dos preços é explicada tanto pela redução na especulação financeira nas commodities quanto por uma menor taxa de crescimento da economia mundial, principalmente, por uma redução da demanda chinesa por estes tipos de produtos.

Em resumo, tem-se que o comportamento dos preços das commodities, em especial das agrícolas, não dependem exclusivamente de mudanças nos fundamentos de mercado, mas da associação desta com a atuação de fundos de investimento especulativos. Na última década, os mercados futuros agrícolas, em que se inclui todos os produtos analisados neste trabalho, passaram a ter grande participação de agentes e instituições que buscam obter, de forma especulativa, ganhos financeiros.

Neste cenário, Hirakuri e Lazzaroto (2011) chamam a atenção também, para a crescente demanda por biocombustíveis, em especial nos mercados de soja e açúcar, que passam a ter relevância em termos de influência sobre a produção e a formação de preços dos produtos em questão. Essa realidade indica que novos elementos estão influenciando a oferta e a demanda desses produtos no mercado mundial. Apesar destes fatos aumentarem a volatilidade no mercado, representam também novas oportunidades de negócio, principalmente para países produtores e detentores de tecnologia como o Brasil.

Quanto as exportações de bens de capital e de bens de consumo duráveis, estas também se elevaram no período em análise, 186,60\% e 230,23\% respectivamente, mas em um ritmo menor do que todas as commodities selecionadas. De acondo com o Gráfico 3.4 tanto o valor exportado dos bens de capital quanto o de bens de consumo duráveis ainda não conseguiram retornar ao patamar do período da crise. Em junho de 2014, os ganhos provenientes do comércio internacional foram $57 \%$ menores do que o ocorrido em setembro de 2008 com os primeiros e 34\% menores com os segundos, além de apresentar uma volatilidade nas vendas para ambos os produtos no período pós-crise muito maior que o do período pré-crise. 
Tabela 3.1 Estatísticas descritivas para preços internacionais e valores exportados das commodities internacionais (01/2000$06 / 2014$

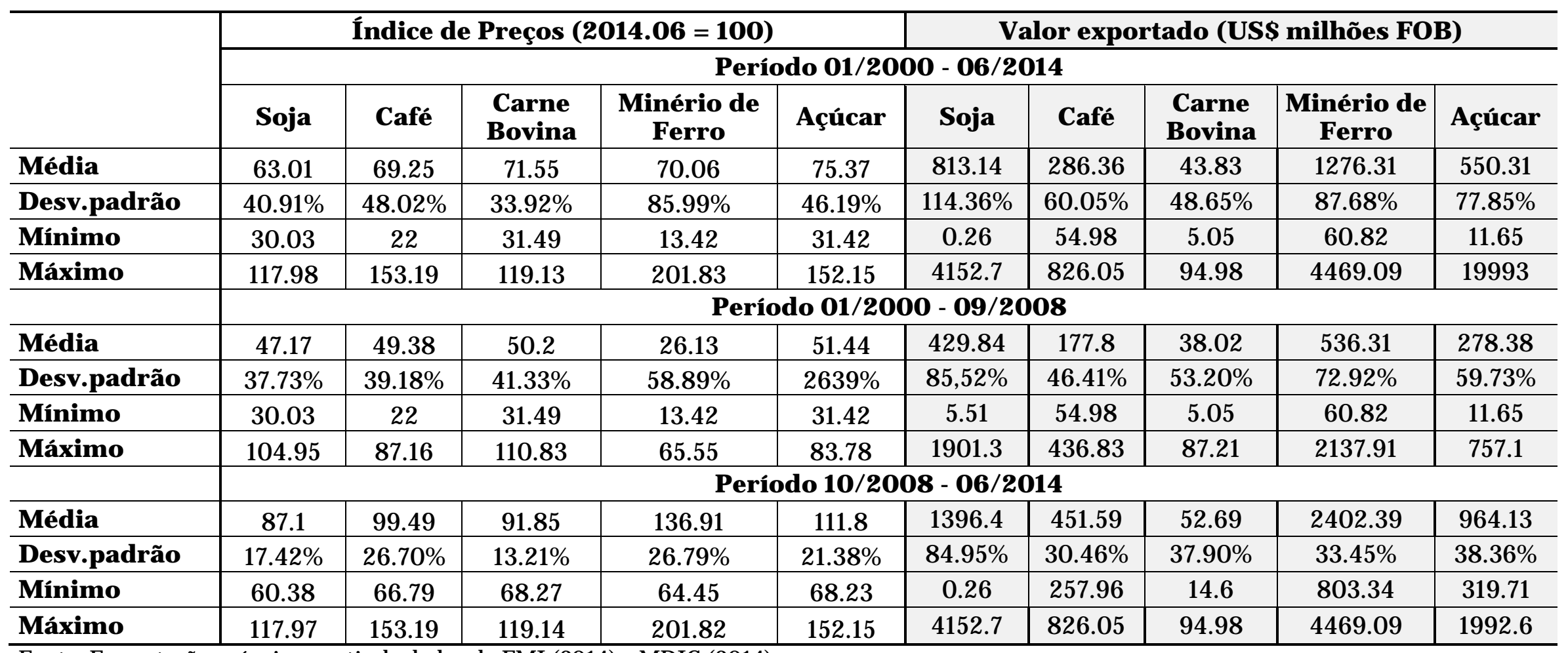

Fonte: Formatação própria a partir de dados do FMI (2014) e MDIC (2014). 
Gráfico 3.4) Valores exportados (US\$ milhões FOB) de produtos manufaturados 3.3a) Bens de capital 3.3b) Bens de consumo duráveis
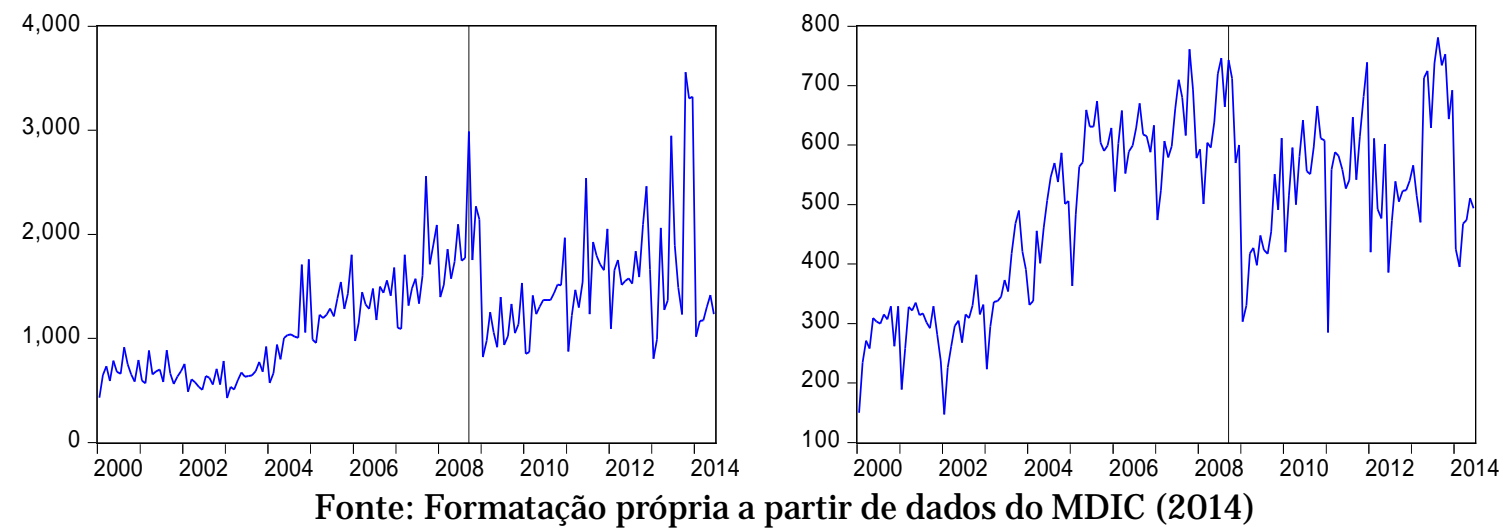

A Tabela 3.2 mostra que a variação dos recursos provenientes de produtos com alto valor agregado é bem menos volátil que a dos produtos primários, em razão principalmente da estabilidade de preços dos produtos oriundos destes mercados. Enquanto a soja apresentou uma dispersão estatística no valor exportado em torno de $114 \%$, em função das características de plantio do produto, os bens de consumo duráveis têm uma variância bastante reduzida em relação a esta commodities, apresentando um valor de $30 \%$ para todo o período e um valor $75 \%$ menor do que o apresentado pela soja para o período pós-crise.

\section{Tabela 3.2 Estatísticas descritivas para os valores exportados de bens manufaturados}

\begin{tabular}{l|c|c|c|c}
\hline \multirow{2}{*}{} & \multicolumn{2}{|c|}{\begin{tabular}{c} 
I00) \\
\cline { 2 - 5 }
\end{tabular}} & \multicolumn{4}{c}{ Período de 01/2000 - 06/ 2014 } \\
\cline { 2 - 5 } & $\begin{array}{c}\text { Bens } \\
\text { Duráveis }\end{array}$ & Bens de Capital & Bens Duráveis & Bens de Capital \\
\hline Média & 93.86 & 94.25 & 1259.19 & 493.08 \\
\hline $\begin{array}{l}\text { Desv.padrã } \\
\text { o }\end{array}$ & $5.34 \%$ & $3.03 \%$ & $46.35 \%$ & $30.25 \%$ \\
\hline Mínimo & 88.33 & 90.51 & 426 & 147 \\
\hline Máximo & 102.49 & 100 & 3557 & 781 \\
\hline Média & \multicolumn{4}{|c}{ Período de 01/ 2000 - 09/ 2008 } \\
\hline $\begin{array}{l}\text { Desv.padrã } \\
\text { o }\end{array}$ & 90.34 & 92.17 & 1067.9 & 458.17 \\
\hline Mínimo & $1.94 \%$ & $1.20 \%$ & $46.87 \%$ & $35.09 \%$ \\
\hline Máximo & 88.33 & 90.51 & 426.3 & 146.8 \\
\hline & 96.79 & 94.88 & 2987.2 & 760.6 \\
\hline Média & 99.22 & 97.41 & 1550 & 546.06 \\
\hline $\begin{array}{l}\text { Desv.padrã } \\
\text { o }\end{array}$ & $1.93 \%$ & $1.51 \%$ & $37.67 \%$ & $20.33 \%$ \\
\hline Mínimo & 95.72 & 94.41 & 804.2 & 284.9 \\
\hline Máximo & 102.5 & 100 & 3557 & 781.3 \\
\hline
\end{tabular}

Fonte: Formatação própria a partir de dados do MDIC (2014) e Bureu of labor Statistics (2016) 
Considerando os Gráficos 3.1, 3.2 e 3.3 e as estatísticas básicas apresentadas nas Tabelas 3.1 e 3.2, pode-se observar que a redução de participação relativa no comércio internacional brasileiro dos bens manufaturados acarreta em uma maior vulnerabilidade externa por parte da economia brasileira, uma vez que os principais produtos exportados pelo Brasil, soja e minério de ferro são aqueles que apresentam a maior volatilidade em termos de valor exportado (em US\$ milhões) - 85\% e 72\% respectivamente - para todo o período de análise.

A partir da análise do comportamento dos preços e do volume vendido dos insumos básicos e dos bens manufaturados, em conjunto com a evolução na participação de ambos na pauta exportadora, onde os primeiros tiveram um aumento expressivo, ampliando de $14 \%$ no início do ano 2000 para quase $40 \%$ no final do primeiro semestre de 2014, enquanto a participação dos bens industriais para o mesmo período apresentou uma retração de $60 \%$ e ainda por ter ocorrido uma apreciação cambial de $32 \%$, constata-se que existem fortes indícios da problemática da doença holandesa no Brasil.

Ressalta-se também que a participação majoritária das commodities na pauta exportadora associada a alta volatilidade inerente a esses produtos em relação aos bens de maior valor agregado pode ocasionar em uma maior instabilidade na balança comercial e trazer complicações macroeconômicas relevantes.

\section{Investigação empírica sobre o impacto da crise financeira de 2008 nas exportações}

Em sintonia com as teorias sobre a hipótese de doença holandesa, as vantagens ricardianas na produção de bens intensivos em recursos naturais e a elevação dos preços internacionais das commodities, que implicam em aumentos de divisas oriundas deste setor, se faz necessário investigar o comportamento da pauta de exportação brasileira para analisar como, por exemplo, condições macroeconômicas globais, o Efeito-China e choques climáticos impactam tanto neste segmento como no de manufaturados, para assim poder obter melhores diagnósticos em relação à questão da "primarização" das vendas internacionais e por consequência da questão da doença holandesa.

Sob tal contexto, o período de análise deste trabalho se estende de janeiro de 2000 a junho de 2014, com periodicidade mensal. Os valores de exportação (milhões de dólares) das commodities soja em grão, minério de ferro, açúcar, café e carne bovina, assim como dos produtos industrializados, bens de capital e bens de consumo duráveis foram obtidos junto ao Ministério do Desenvolvimento, Indústria e Comércio Exterior (MDIC, 2014) e conforme orienta a literatura (PERRON, 2003) as séries foram transformadas em logaritmos antes da aplicação dos testes de quebra estrutural. Segundo dados do mês de junho de 2014, estes produtos representavam $44 \%$ do total exportado pelo país e por isto, tais variáveis foram selecionadas para a análise de impacto da crise financeira internacional.

Para analisar as possíveis mudanças estruturais que possam ter ocorrido ao longo dos anos 2000, foram feitos os seguintes testes: Teste de Múltiplas Quebras segmentado proposto por Bai e Perron (2003) e Zivot e Andrews (2002). Todos estes procedimentos foram feitos utilizando o software Eviews 8.1. 
O teste de Bai-Perron (2003) ${ }^{1}$ de múltiplas quebras estruturais com base de dados segmentada considera um teste com hipótese nula de, digamos l quebras contra a hipótese alternativa de l+1 quebras. Tal procedimento permite uma visão do específico para o geral, além de poder ser construído permitindo diferentes padrões de correlação serial nos erros e nas distribuições dos erros entre as quebras.

A Tabela 4.1 apresenta os resultados obtidos para o teste e na sequência os Gráficos 4.1a, 4.1b e 4.1c apresentam as quebras obtidas para a série de bem de capital, bem de consumo durável e minério de ferro.

Percebe-se pela análise da Tabela 4.1 e do Gráfico 4.1 que a crise financeira de 2008 teve impacto apenas na exportação do minério de ferro, enquanto nenhum outro produto parece ter sido significativamente influenciado. Quanto a exportação de bens manufaturados a crise não apresentou nenhuma influência, ou seja, a tendência de redução de participação no valor total exportado pelo país continua, mas sem afetar no ritmo dessa trajetória.

Tabela 4.1 Teste de Múltiplas Quebras Bai-Perron (2003)

\begin{tabular}{|c|c|c|}
\hline Indicadores & Quebras & t-stat \\
\hline \multirow{2}{*}{ Açúcar } & $2005 \mathrm{~m} 05$ & 22.08 \\
\hline & $2009 \mathrm{~m} 05$ & 24.78 \\
\hline Soja & $2003 \mathrm{~m} 03$ & 8.79 \\
\hline \multirow{2}{*}{ Carne Bovina } & $2003 \mathrm{~m} 06$ & 31.56 \\
\hline & $2011 \mathrm{~m} 08$ & 11.95 \\
\hline \multirow{2}{*}{ Café } & $2004 \mathrm{~m} 06$ & 32.64 \\
\hline & $2006 \mathrm{~m} 08$ & 45.78 \\
\hline \multirow{3}{*}{ Minério de Ferro } & $2004 \mathrm{~m} 03$ & 38.61 \\
\hline & $2006 \mathrm{~m} 06$ & 67.64 \\
\hline & $2010 \mathrm{~m} 05$ & 19.58 \\
\hline Bens de Capital & $2004 \mathrm{~m} 05$ & 288.7 \\
\hline $\begin{array}{l}\text { Bens de Consumo } \\
\text { Duráveis }\end{array}$ & 2003 m08 & 153.02 \\
\hline
\end{tabular}

Fonte: Formatação própria partir dos resultados do teste de múltiplas quebras segmentadas. Todos os resultados são estatisticamente significantes ao nível de significância de 5\%.

O teste de raiz unitária de quebra estrutural proposta por Zivot e Andrews (1993) procura determinar endogenamente a data da quebra estrutural.

Este modelo é uma das mais importantes ferramentas utilizada para detectar tais alterações, pois investiga a presença da quebra estrutural no nível, na tendência ou em ambos da série estudada. A hipótese nula desse modelo é de que não há quebra estrutural, isto é, existe raiz unitária, enquanto que a alternativa é uma série estacionária com quebra estrutural que pode ocorrer em qualquer data.

\footnotetext{
1 Para um melhor entendimento, favor ver Bai, J.; Perron, P. (2003a). Computation and Analysis of Multiple Structural Change Models. J oumal of Applied Econometrics, 18(1), 1-22.
} 
Gráfico 4.1 Gráfico de quebras estruturais

Gráfico 4.1a) Bem de capital

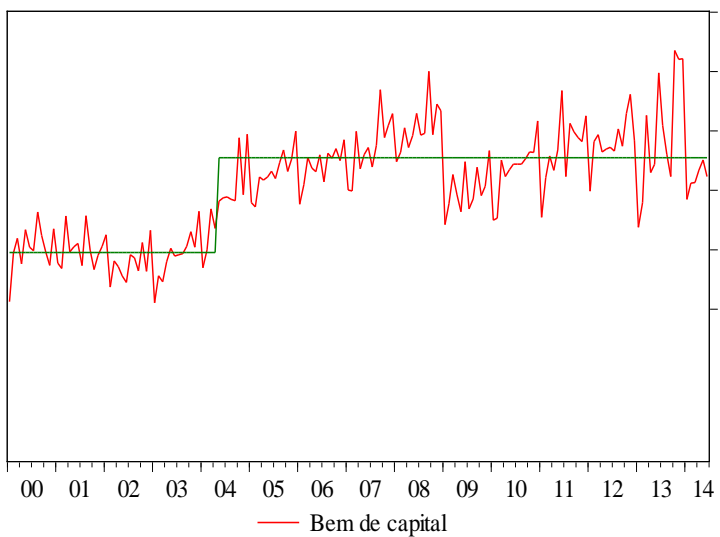

Gráfico 4.1c) Soja em grão

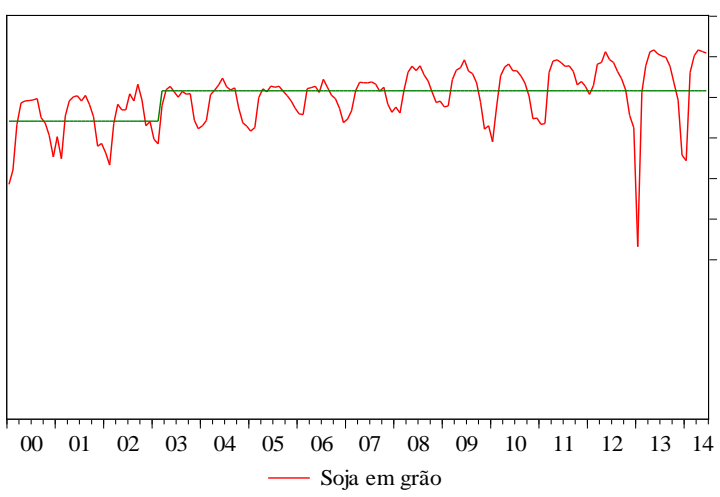

Gráfico 4.1b) Bem de consumo durável

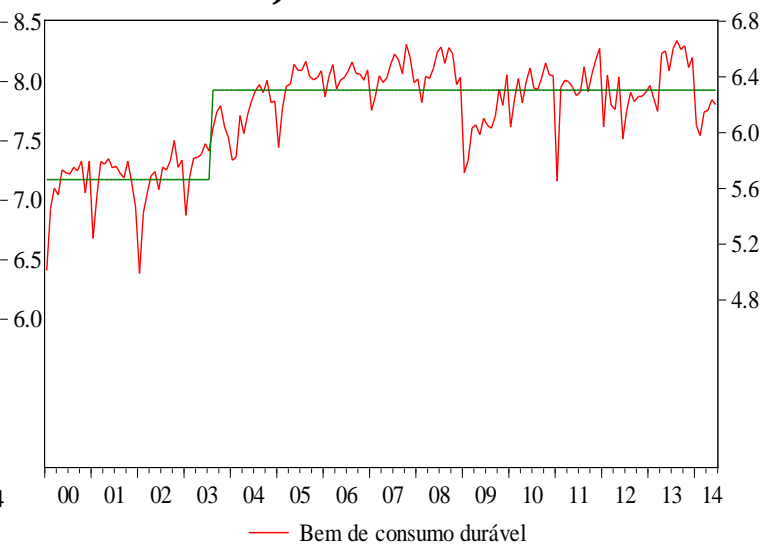

Fonte: Dados da pesquisa

Gráfico 4.1d) Minério de Ferro

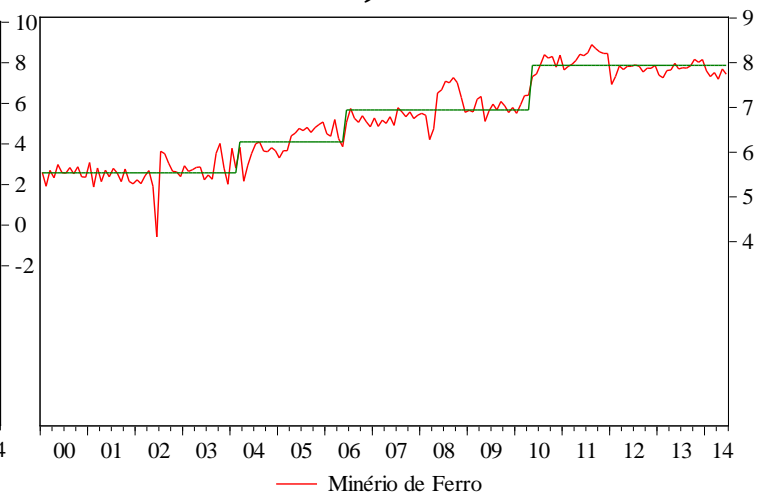

A Tabela 4.2 apresenta os resultados para os três casos:

Tabela 4.2 Teste de raiz unitária de Quebra Estrutural ZivotAndrews (2002)

\begin{tabular}{|c|c|c|c|c|c|c|}
\hline Indicadores & Nível & t-stat & Tendência & t-stat & Ambos & t - stat \\
\hline Açúcar & $2011 \mathrm{~m} 02$ & -6.63 & $2011 \mathrm{~m} 09$ & -6.79 & $2010 \mathrm{m05}$ & -6.64 \\
\hline Soja & 2003m 03 & -8.62 & $2008 \mathrm{~m} 06$ & -8.52 & $\begin{array}{l}2003 \\
\text { m03 }\end{array}$ & -8.59 \\
\hline Carne Bovina* & $2008 \mathrm{~m} 02$ & -5.34 & 2003 m10 & $-3,49$ & $\begin{array}{l}2008 \\
\mathrm{~m} 02\end{array}$ & -6.77 \\
\hline Café & 2012m 01 & -5.28 & $2011 \mathrm{~m} 09$ & -5.06 & $2010 \mathrm{m07}$ & -5.57 \\
\hline $\begin{array}{l}\text { Minério de } \\
\text { Ferro* }\end{array}$ & 2012 m01 & $-3,81$ & $2011 \mathrm{~m} 10$ & $-3,94$ & $2010 \mathrm{~m} 05$ & -5.10 \\
\hline Bens de Capital & $2009 \mathrm{~m} 01$ & -5.37 & $2007 \mathrm{~m} 04$ & -4.47 & $2009 \mathrm{m01}$ & -5.60 \\
\hline $\begin{array}{l}\text { Bens de } \\
\text { Consumo } \\
\text { Duráveis* }\end{array}$ & $2004 \mathrm{~m} 03$ & -5.74 & $2005 \mathrm{~m} 12$ & -5.47 & $\begin{array}{l}2008 \\
\text { m11 }\end{array}$ & $-5,03$ \\
\hline \multicolumn{7}{|c|}{$\begin{array}{l}\text { Fonte: Formatação própria a partir dos resultados do teste de Zivot-Andrews . Todos os } \\
\text { resultados são estatisticamente significantes ao nível de significância de } 5 \% \text {. } \\
\text { * Não são estatisticamente significantes a } 5 \% \text { - Testes para tendência da carne bovina, nível e } \\
\text { tendência para o minério de ferro e nível e tendência juntos para bens de consumo duráveis não } \\
\text { foram insignificantes neste nível. }\end{array}$} \\
\hline
\end{tabular}


Corroborando com os resultados apresentados no teste anterior, a crise de 2008 parece não ter provocado efeitos significativos sobre as variáveis selecionadas. Apenas em um caso, para bens de capital, quando se realiza o teste tanto para nível quanto para inclinação simultaneamente que a crise pode ter influenciado com alguma defasagem as exportações deste item. É interessante notar também que a rejeição da hipótese nula na maioria dos testes evidencia o fato de que perturbações de curto prazo nas séries são permanentes e incorporam-se na tendência de longo prazo das mesmas. Isso significa que políticas macroeconômicas, assim como políticas de determinação de preço, de duração de contratos futuros e choques de oferta e demanda de curto prazo, podem influenciar, pelo menos em algum grau, a trajetória de longo prazo destas variáveis.

\section{Conclusão}

Este trabalho tem por objetivo contribuir para o debate sobre o processo de "primarização" da pauta exportadora, da questão da doença holandesa no Brasil e avaliar os efeitos da crise financeira de 2008 nestes dois temas. Para tal, utilizou-se como medidas de análise o valor das exportações de soja em grão, minério de ferro, café, carne bovina, açúcar, bens de capital e bens de consumo duráveis e suas respectivas participações no valor total das exportações brasileira.

Conforme apresentado ao longo do artigo, os sintomas que advertem sobre esses problemas, principalmente após o boom dos preços das commodities metálicas e agrícolas em 2002, são:

a) aumento superior médio dos valores exportados das commodities em relação aos bens manufaturados;

b) a participação relativa no saldo total das exportações dos produtos que geram a doença holandesa evoluiu positivamente no período analisado, aumentando de $16,46 \%$ em junho de 2000 para 35,18\% em junho de 2014, enquanto a dos manufaturados sofreu uma redução de $48,78 \%$ no mesmo intervalo de tempo.

Para verificar o efeito da crise financeira foram realizados os testes de múltiplas quebras estruturais com dados segmentados propostos por Bai-Perron (2003) e o de raiz unitária com quebra estrutural de Zivot e Andrews (2002). Os resultados indicaram que praticamente nenhuma variável apresentou mudança estatisticamente significativa em relação a este evento. Apenas em um dos testes realizados (Zivot-Andrews para nível) as exportações de bens de capital aparentam ter sofrido uma mudança estrutural em nível, mas a sua tendência não foi afetada. Assim, com estas evidências fica claro, o impacto praticamente nulo da crise financeira de 2008 sobre as exportações brasileiras. Tal resultado implica que a crise de 2008 não atenuou o processo de "reprimarização" da pauta de exportação. $\mathrm{O}$ fato de não ter havido mudanças na pauta nos períodos analisados, pode ser explicado por problemas de contratos longos, rigidez na estrutura produtiva, utilização de matéria prima para diversos fins, produção em grande escala e uma estrutura produtiva consolidada.

Portanto este trabalho corrobora com as conclusões de outros autores acerca da 
“Doença Holandesa" e da "primarização" das exportações no Brasil, devido ao alto volume de exportação de commodities, preço elevado e apreciação cambial. Todavia, uma análise mais fina para verificar quais setores são os mais afetados é fundamental para que se possam definir políticas eficazes no sentido de evitar a continuidade de um processo de perda de importância do setor manufatureiro nas exportações nacionais, que atinge a economia brasileira no Século XXI.

\section{REFERÊNCIAS BIBLIOGRÁFICAS}

AREND, M. A industrialização do Brasil ante a nova divisão internacional do trabalho. In: In: IPEA. Presente e Futuro: desafios ao desenvolvimentismo brasileiro. IPEA, 2014.

AREND, Marcelo; FONSECA, Pedro Cezar Dutra. Brasil (1955-2005): 25 anos de catching up, 25 anos de falling behind. Revista de Economia Política, v. 32, n. 1, p. 33-54, 2012.

BAI, J.; PERON, P. Computation and Analysis of Multiple Structural Change Models. J ournal of Applied Econometrics, 18(1), 1-22, 2003a.

BAI, J; PERON, P. Critical Values for Multiple Structural Change Tests. Econometrics J ournal, 6, 72-78, 2003b.

BANCO CENTRAL DO BRASIL. Relatório Anual 2009. Brasília. v.45, p. 1-237, 2009.

BRESSER PEREIRA, L. C. Doença holandesa e sua neutralização: uma abordagem ricardiana. Revista de Economia Política, n. 28, dez 2007, p. 47-71.

BRESSER-PEREIRA, L. C.; MARCONI, N. Existe doença holandesa no Brasil? IV Fórum de Economia da Fundação Getúlio Vargas. 2008. 20 p.

BRESSER-PEREIRA, L. C.; MARCONI, N.; OREIRO, J. L. A doença holandesa. Globalização e competição: por que alguns países emergentes têm sucesso e outros não. Rio de J aneiro: Elsevier, p. 141-171, 2009.

BRESSER-PEREIRA, L. C.; GALA, P. Macroeconomia estruturalista do desenvolvimento. Revista de Economia Política, v. 30, n. 4, p. 663-686, 2010.

Bureu of labor Statistics. United States Departament of Labor. Acesso em dezembro de 2016. Disponível em: www.bls.gov/web/ ximpim.supp.toc.htm

BONELLI, R.; PESSOA, S. A. Desindustrialização no Brasil: um resumo da evidência. Texto para Discussão, Rio de J aneiro: FGV/ IBRE, 2010.

CANO, W. Industrialização e (sub) desenvolvimento. Cadernos de Desenvolvimento, CICEF, Rio de J aneiro, v. 9, n. 15, p. 139-175, 2014.

CARNEIRO, R. Impasses do desenvolvimento brasileiro: a questão produtiva. Textos para Discussão, Campinas: IE/ UNICAMP, n. 153, nov. 2008.

CARNEIRO, R. O Desenvolvimento Brasileiro Pós-Crise Financeira: Oportunidades e Riscos. Observatório da economia global. Textos avulsos n.4, ago, 2010.

COMIN, A. A desindustrialização truncada perspectivas do desenvolvimento econômico brasileiro. Universidade Estadual de Campinas - Instituto de 
Economia Programa - Pós-Graduação em Economia, Tese, Unicamp, 2009.

CORDEN W. M. Booming sector and dutch disease economics: survey and consolidation, In: Oxford Economic Papers, vol. 36, no 3, nov-1984.

CORDEN, W. M, ; NEARY, J. P. Booming sector and de-industrialisation in a small open economy, In: Economic J ournal, vol. 92, no 368, dez-1982.

FERRAZ, J. C.; KUPFER, D.; IOOTTY, M. Competitividad Industrial en Brasil 10 años después de la liberalización. Revista de la CEPAL, v. 82, p. 91-119, 2004.

IMF. IMf primary commodity prices. International Monetary Fund. Data and Statistics. Acesso em Setembro de 2014.

IPEADATA. Base de Dados do Instituto de Pesquisa em Economia Aplicada (IPEA). Macroeconômico. 1. Acesso em março de 2016.

HIRAKURI, M. H.; LAZZAROTTO, J. J. Evolução e perspectivas de desempenho econômico associadas com a produção de soja nos contextos mundial e brasileiro. Londrina, PR: EMBRAPA, 2011.

LAPLANE, M.; SARTI, F. Prometeu acorrentado: o Brasil na indústria mundial no início do século XXI. Política Econômica em Foco, n. 7, p. 271-291, 2006.

MDIC. Estatísticas de Comércio Exterior (AliceWeb) - Balança comercial Brasileira Mensal. Ministério do Desenvolvimento, Indústria e Comércio Exterior. Acesso em setembro de 2014

MORCEIRO, P. C.; Desindustrialização na economia brasileira no período de 2000 a 2011: abordagens e indicadores. Programa de Pós-Graduação em Economia (Dissertação) - Universidade Estadual Paulista, Araraquara, 2012. $219 \mathrm{f}$.

PASTORE, A.F.; PINOTTI, M.C. A Crise de 2008 e o Brasil. Fórum Nacional Edição extraordinária. Estudos e pesquisa n.259, 2008.

SARTI, F. HIRATUKA, C. Indústria mundial: mudanças e tendências recentes. In: SARTI, F. HIRATUKA, C. (org.) Perspectivas do investimento no Brasil: indústria. RJ : Synergia, v.1, p. 1-42, 2010.

SARTI, F.; HIRATUKA, C. Investimento direto e internacionalização de empresas brasileiras no período recente. In: Texto de Discussão. IPEA, no. 1610, 2011, 56 p.

STRACK, D.; AZEVEDO, A. F. Z. A doença holandesa no Brasil: sintomas e efeitos, Revista Economia e Desenvolvimento, v. 24, n.2, p. 68-91, 2012,

TORRES, R. L.; CAVALIERI, H. Uma crítica aos indicadores usuais de desindustrialização. Revista de Economia Política, v. 35, n. 4, p. 859-877, Out. 2015.

VERÍSSIMO, M. Doença holandesa no Brasil: ensaios sobre taxa de câmbio, perfil exportador, desindustrialização e crescimento econômico. Universidade Federal de Uberlândia - Instituto de Economia, Programa De Pós-Graduação em Economia, Tese, UFU, 2010.

ZIVOT, E.; ANDREWS, D. Further evidence on the great crash, the oil-price shock and the unit root hypothesis. Journal of Business and Economic, Statistics, ASA, v.20, n.1, p. - 25-44, 2002. 